\title{
UM NEGÓCIO AGRO: A POSIÇÃO SUJEITO FEIRANTE E OS PROCESSOS DE IDENTIFICAÇÃO EM SINOP-MT
}

Débora Pereira Lucas Costa ${ }^{1}$

Resumo: O Ministério de Desenvolvimento Agrário estima que 70\% dos alimentos consumidos pelos brasileiros provém da agricultura familiar. As feiras livres estão entre as formas de comercialização desse resultado produtivo. A visão nacional desse setor desperta-nos curiosidade e faz com que voltemos o olhar para Sinop-MT, onde as feiras surgiram com o processo de construção da cidade e ainda permanecem na economia local. Interessamo-nos pela relação entre o agricultor, na posição feirante, e o agronegócio, a fim de compreender os processos identificação, seguindo os pressupostos de Michel Pêcheux e Eni Orlandi, no campo da Análise do Discurso.

Palavras-chave: discurso; agronegócio; feirante; agricultura familiar

\begin{abstract}
The Ministry of Agrarian Development estimates that $70 \%$ of the food consumed by brazilians comes from family farming. The free trade fairs are among the forms of commercialization of this productive result. The national vision of this sector awakens curiosity and makes us look back at Sinop-MT, where the fairs emerged with the construction process of the city and still remain in the local economy. We are interested in the relationship between the farmer, in the marketer position, and agribusiness, in order to understand the processes identification, following the assumptions of Michel Pêcheux and Eni Orlandi, in the field of Discourse Analysis.
\end{abstract}

Keywords: discourse; agribusiness; marketers; family farming

\section{Introdução}

Quando se fala em agricultura familiar, associa-se o setor à sua importância quanto ao cultivo de alimentos e à fixação do homem no campo, enquadrando a atividade em uma função mais social do que econômica. No entanto, vale destacar que a produção além das características de subsistência, também é geradora de recursos. A agricultura familiar brasileira - definida pela Lei 11.326/2006 como aquela que engloba atividades em propriedades no meio rural com área de até quatro módulos fiscais, mão de obra da família e rendimento vinculado ao próprio

\footnotetext{
1 Mestranda do Programa de Pós-graduação em Letras da Universidade do Estado do Mato Grosso (PPGLetras/UNEMAT). Pesquisadora do Grupo de Pesquisa Educação Científico Tecnológica e Cidadania. Email: deborajor@hotmail.com
} 
estabelecimento - é responsável pela renda de $40 \%$ da população economicamente ativa do País, segundo dados do Governo Federal.

No Brasil, as feiras livres - um formato de venda ao varejo -, constituem-se de um movimento que cria e mantém relação próxima entre quem produz e quem consome alimentos. Esses espaços de comercialização da produção do campo geralmente ocorrem em locais estratégicos de centros urbanos, em dias e horários determinados, e são, segundo Pereira e Brito (2017), um espaço de socialização, identidade regional, cultural e de articulação política. 'Nas feiras há movimentação de produtos, pessoas, informações e cultura, numa dinâmica muito peculiar, que se mistura com a paisagem local" (PEREIRA e BRITO, 2017, p. 01).

Essas descrições podem ser reforçadas pelo que diz Menezes (2005), quando afirma que a relação direta entre quem consome e quem produz reduz os custos da comercialização, tornando a feira um meio eficiente e direto entre os interessados. Em Sinop, município localizado na região Médio-Norte do Estado de Mato Grosso, pode-se perceber que esse canal direto entre o produtor e consumidor final é marcado pela circulação de muitos munícipes que vivem em uma cidade cuja economia está alicerçada na produção agropecuária e na atividade extrativista desde sua fundação, em 1974. As grandes propriedades rurais localizadas no município convivem com as pequenas chácaras, e o trabalho do campo é indissociável ao crescimento desse espaço da Amazônia brasileira.

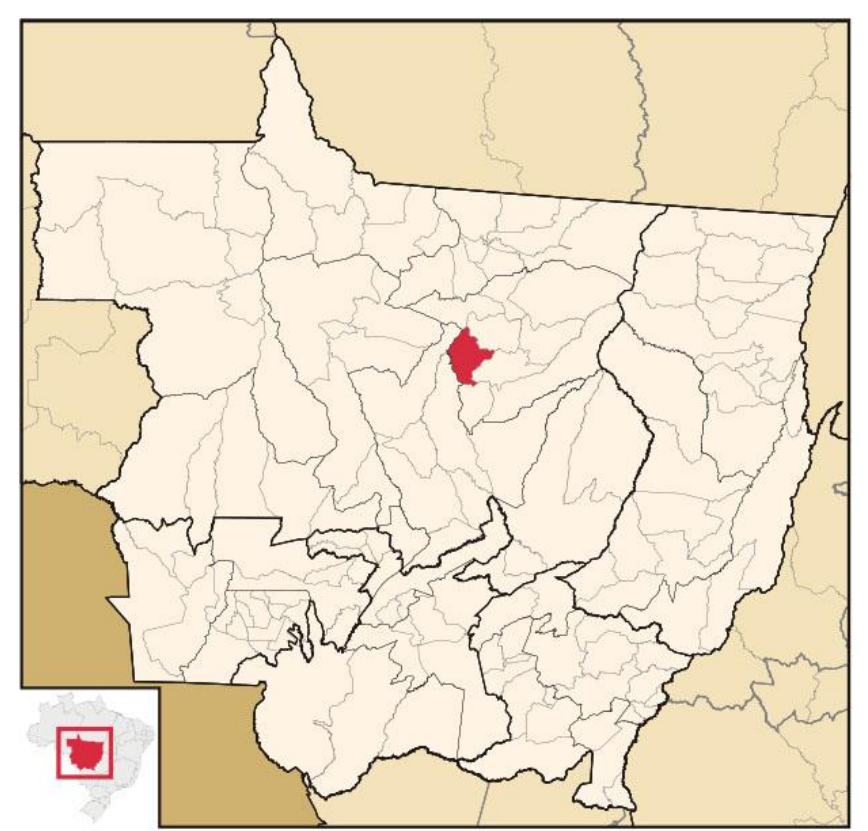

Figura 1 - Mapa que localiza o município de Sinop dentro do Estado de Mato Grosso. IBGE (2016) 
Em um Mato Grosso que se orgulha da alcunha de 'celeiro do Brasil', inclusive sendo assim descrito no site institucional do Governo do Estado, muito se ouve falar na produção de grãos em larga escala, facilmente associada à formulação agronegócio. E, se a Análise do Discurso materialista histórica sustenta que os sentidos são produzidos em decorrência da ideologia dos sujeitos, interessa-nos compreender o sujeito feirante de Sinop-MT em seus processos de identificação, levando em conta esse imaginário social que envolve o agronegócio. Partimos de uma acepção que integra o cotidiano mato-grossense, advinda do senso comum, de que o agronegócio refere-se às grandes propriedades e aos grandes volumes de produção. Tratase, portanto, de um saber da ordem do discurso, que se encontra em uma memória que é de natureza social, que não se consegue precisar. Isso pode ser entendido se recorrermos a Orlandi (2015, p. 29), quando ela explica: “o saber discursivo que torna possível todo dizer e que retorna sob a forma do pré-construído, o já-dito que está na base do dizível, sustentando cada tomada de palavra".

Partindo do pré-construído sobre o agronegócio e sobre a agricultura familiar, essee texto, que integra as atividades do Grupo de Pesquisa Educação Científico-Tecnológica e Cidadania, da Universidade do Estado de Mato Grosso (Unemat/Sinop), toma como objeto de análise, os discursos de dois feirantes que participam efetivamente nas feiras de Sinop-MT, tendo a Análise do Discurso materialista-histórica como teoria base e método de pesquisa. Busca-se compreender como o agronegócio significa no discurso desses dois sujeitos.

\section{Os sujeitos e a situação}

Partindo do entendimento de que o sujeito discursivo está inserido em uma conjuntura social, com marcas históricas e ideológicas torna-se necessário delinear as condições de produção dos discursos que interessam a essa pesquisa. Orlandi (2015, p. 28) ressalta que as condições de produção compreendem fundamentalmente os sujeitos e a situação. Os dizeres são, portanto, pistas, a serem seguidas pelo analista do discurso "para compreender os sentidos aí produzidos, pondo em relação o dizer com sua exterioridade."

Sob a organização da Associação dos Feirantes de Sinop (Afes), as feiras voltadas aos sinopenses acontecem de segunda-feira a sábado, nos bairros Jardim Botânico, Jardim Palmeiras, Jardim Primavera e Aquarela Brasil, em sua maioria com instalações provisórias, onde cada feirante monta sua banca ao lado de outros, em espaços públicos. Isso não ocorre, apenas quando as feiras são organizadas no bairro Jardim Botânico, onde uma estrutura fixa foi 
construída pela prefeitura e os feirantes pagaram pela aquisição de seus espaços. O que se oferta nas feiras retrata a produção agropecuária da região: legumes, frutas, produtos de origem animal e seus derivados, como doces, queijos e temperos. Essa diversidade garante a regularidade da comercialização, respeitando a sazonalidade de alguns produtos.

Caminhando entre as barracas das feiras é possível encontrar Gilson Wolf. Nascido na cidade de Cunha Porã, em Santa Catarina, ele mudou-se para Sinop-MT com os pais, em 1989, com o objetivo de trabalhar na produção agrícola do município. Desde 2000, atua nas feiras sinopenses e, junto à esposa, administra uma banca. $\mathrm{O}$ irmão assumiu o espaço que era do pai. Atualmente, Gilson é o presidente da Afes e sintetiza como as atividades funcionam:

Os feirantes escolhem uma mercadoria que seja produtiva em Sinop e trazem para a feira o que o pessoal procura. Quem produz para a feira, vende tudo na feira. Uns poucos também vendem para mercados, mas são poucos. Temos feiras todos os dias. Cada dia em um bairro da cidade. Tem gente que vai em todos os bairros, outros vão só em alguns.

Nota-se que o que será levado para a feira é decidido pelo feirante de acordo com a sua capacidade de produção. O trecho da entrevista corrobora com a ideia de Pereira e Brito (2017) de que a feira pode representar um lugar de preservação das relações socioculturais, dos aspectos peculiares ao ambiente rural, da autonomia do (da) agricultor (a) e do fortalecimento dos laços e do saber local.

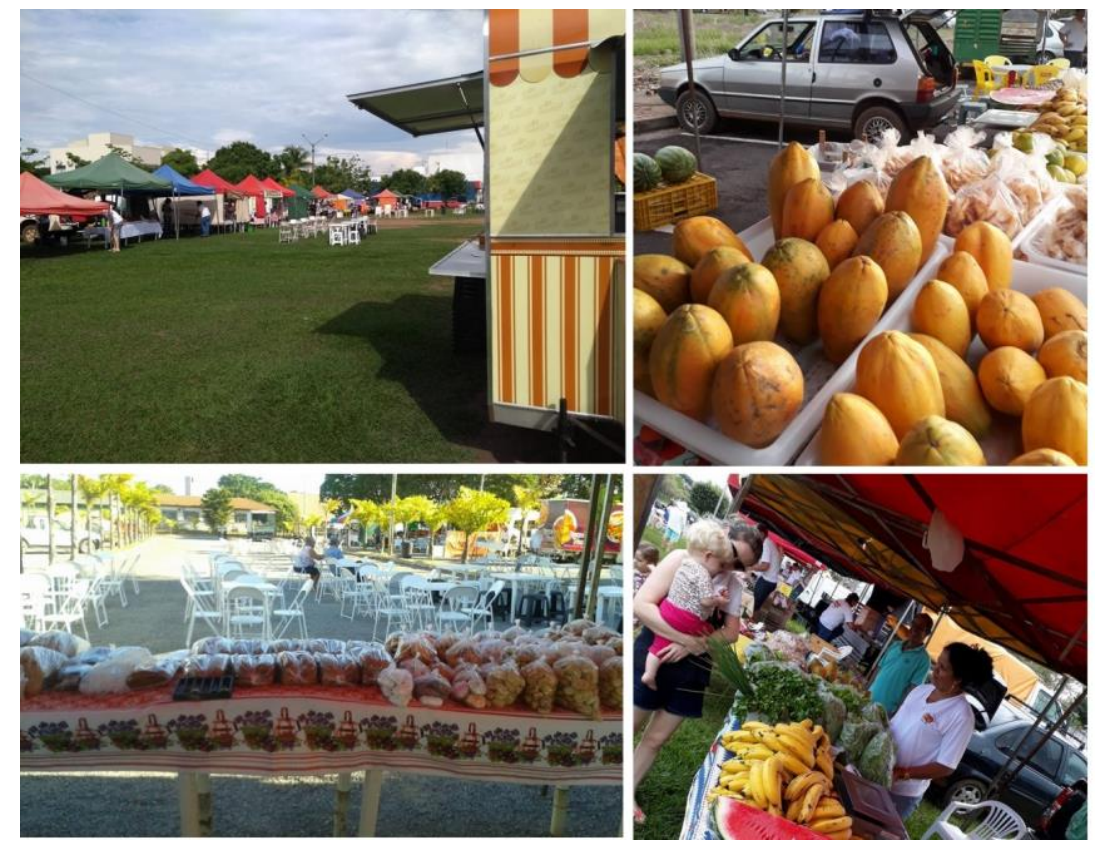

Figura 2 - Feira promovida pela Associação dos Feirantes de Sinop - AFES. Reprodução Facebook. 
Para pensar sobre os efeitos de sentido que estão funcionando, a Análise do Discurso volta-se à observação do homem falando, das palavras em movimento, dos discursos de sujeitos que estão sempre assujeitados à situações. Nessa busca por entender o discurso que é o encontro da língua com a história, também voltamos nosso olhar para um dos primeiros vendedores de hortaliças do município de Sinop. Ele atuou na liderança dos feirantes ao longo de décadas. Beno Asseburg deixou a colônia de Witmarsum, no Paraná, em 1974, e mudou-se para Sinop, junto com a esposa Hildegard Asseburg. Ele conta que o objetivo inicial era montar uma serraria, o que não aconteceu. Como não havia produção de verduras na cidade, Beno e a esposa mantinham sua própria horta. A produção agradou aos vizinhos, que, segundo Beno, sempre pediam um pimentão, um pepino, entre outros, impulsionando a embrionária atividade feirante em Sinop.

Ai a gente começou a vender na vila, que tinha 25 casas, isso em 1974, 1975. Decidi plantar em quantidade maior, mudamos pra chácara e levávamos para a cidade com um tratorzinho reboque. Plantava verdura e ia vender na vila. Voltava vazio. Aí eu pensei, tem que fazer uma feira livre. Um conhecido meu tinha o fundo do lote livre e pedi se podia montar uma barraquinha para vender ali. Comecei e deu um movimento que ficava fila ali esperando. Cidade pequena. Isso era em 1977, 78. Aí outros queriam vender também, e eu dizia, fica do lado aí, fica na calçada. Aí o seu Geraldino, prefeito da época, viu e disse tem uma quadra livre ali na frente do hospital celeste pode fazer ali a feira. Aí juntou três, quatro. Era muito simples.

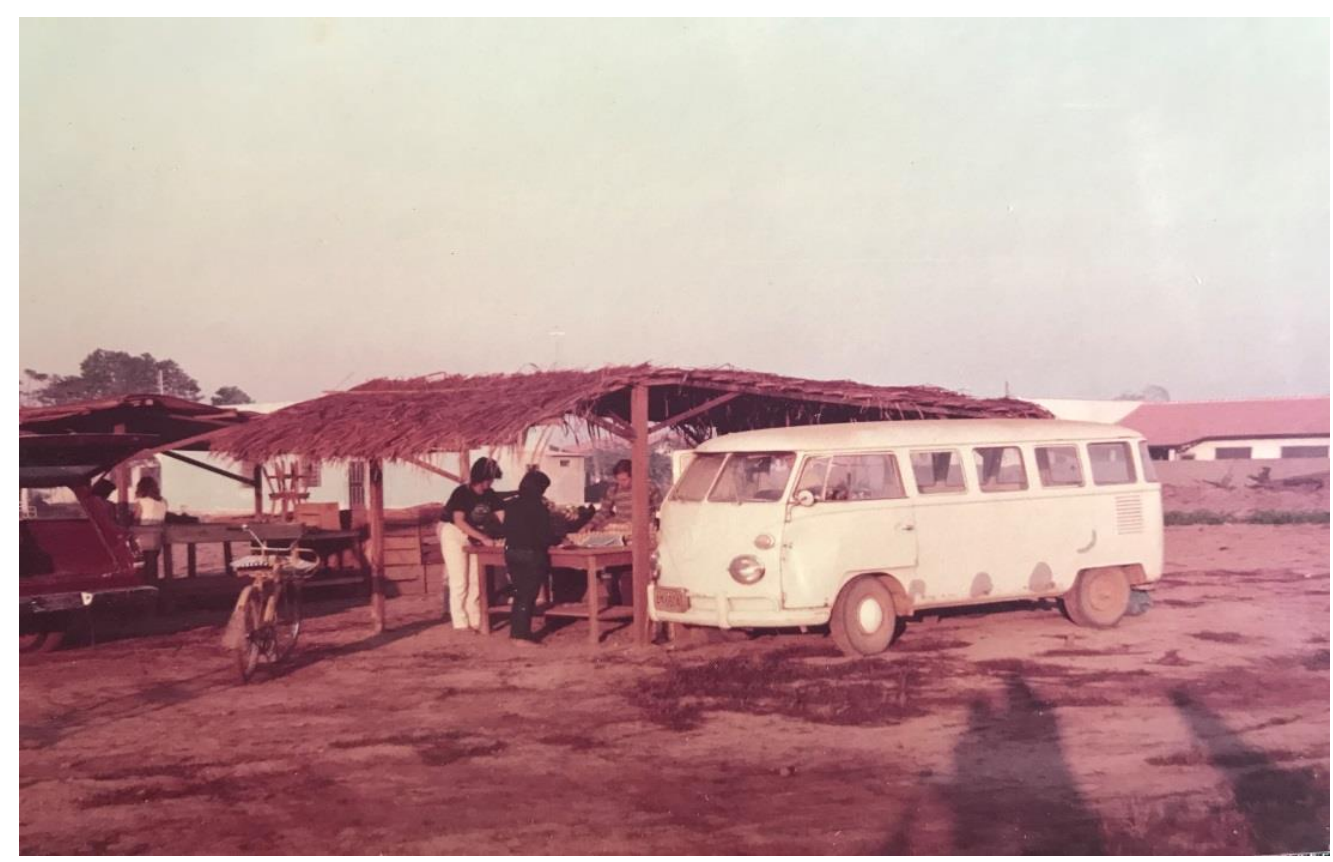

Figura 3 - Primeira feira de Sinop-MT, em 1982. Arquivo pessoal Beno Assenburg 
Percebe-se que Gilson e Beno são sujeitos que escolhem o que dizem, mas seus discursos são determinados pela exterioridade, pela ideologia, por suas relações com a história, pelas formações sociais que os constituem, portanto, pelas condições de produção, que implicam na produção de imagens e definem formulações. Vemos aqui os indivíduos interpelados em sujeitos pela história e pela ideologia. Beno e Gilson falam na posição-sujeito feirante. Orlandi (2015, p. 47) destaca que o sujeito discursivo é pensado como "posição". O que ele diz deriva da formação discursiva em que se inscreve, subjetivando-se na medida mesmo em que se projeta de sua situação (lugar) no mundo para sua posição no discurso" (ORLANDI, 2015, p. 17). E se o sujeito fala de um determinado lugar social, afetado por relações de poder, Gilson e Beno são feirantes, com forte ligação com o processo de desenvolvimento e fortalecimento das feiras de Sinop, ambos assumindo lugares de poder, de comando, de coordenação frente à Associação de feirantes de um município de economia baseada na produção rural, ainda que mais fortemente ligada aos cultivos de soja e milho em larga escala.

\section{Um negócio agro... de qualquer tamanho}

A atividade agropecuária brasileira aparece em posição de destaque na mídia, nos pronunciamentos de lideranças políticas, nas conversas de bar. O falado agronegócio é um conceito adotado pelos brasileiros na década de 1990. A visão, que engloba as atividades 'antes', 'dentro' e 'depois da porteira' de uma propriedade rural, foi trazida para o Brasil por Ney de Araujo, Ivan Wedekin e Luiz Antonio Pinazza, com o lançamento do livro Complexo Agroindustrial: o "agribusiness brasileiro". A ideia de uma atividade de interrelação entre cadeias que são abraçadas pelo conceito de agribusiness foi apresentada pela primeira vez em 1955, por John Davis, em um Congresso de Distribuição de Produtos Agrícolas, em Boston (EUA), e instituído como disciplina, em 1957, por Davis e Ray Goldberg, com o lançamento, em Harvard (EUA), do livro A Concept of Agribusiness - O Conceito de Agribusiness. A nova terminologia refere-se, então, à "soma total de todas as operações envolvendo a produção e distribuição de suprimentos agrícolas; as operações de produção na fazenda; e o armazenamento, processamento e distribuição de produtos agrícolas e dos itens produzidos com eles" (ARAUJO, WEDEKIN e PINAZZA, 1990, p. 13).

Ainda em uma visão científica, Souza (2013) apresenta o agronegócio como uma prática de controle social, na qual o campo é visto como um espaço de lutas entre dominantes e dominados em torno de determinado capital desigualmente distribuído e acumulado. Nos dois 
olhares sobre o agronegócio, não fica explicito que há tamanho de propriedade definido ou quantidade de produção para que uma atividade possa ser enquadrada como agronegócio. Há, sim, um olhar voltado para a atividade comercial envolvendo a atividade rural. Isso reforça a percepção de que há um pré-construído funcionando na produção de sentidos da formulação.

A relação entre o capital e a atividade produtiva também está estabelecida no falar dos sujeitos-feirantes. Sobre sua produção de hortaliças na década de 1970, em Sinop, Beno conta: “era um bom negócio. Com o lucro das verduras eu destoquei a minha chácara, fui fazendo o destocamento, tirava o mato e podia aumentar a produção”. A formulação negócio associada ao cultivo da terra também é percebida no relato de Gilson:

Ah isso é um negócio. Eu trabalho a minha vida toda aqui. É um negócio do campo.
Dependemos da cidade para vender nossa mercadoria, mas é um negócio do campo.
(...) É tudo encostado na cidade. As chácaras nas localidades da Brígida, Nossa
Senhora de Fátima, alguns são da Gleba Atlântida (...), são chácaras, sítios, de dez
hectares, 25 alqueires. Todo mundo não chega a 100 hectares de terra, e a feira é o
que praticamente sustenta todo mundo. São pequenos produtores que produzem na
propriedade e vêm vender na cidade.

Henry (1993, p. 25) ao falar sobre a Análise do Discurso desenvolvida por Michel Pêcheux explica que o que "precisa ser compreendido é como os agentes desse sistema reconhecem eles próprios seu lugar sem terem recebido formalmente uma ordem, ou mesmo sem "saber" que têm um lugar definido no sistema de produção" e ressalta que a ideologia tem a função de fazer com que os agentes reconheçam seu lugar nas relações sociais de produção. Ressignificando o pré-construído de que o agronegócio está associado a latifúndios, os sujeitos feirantes subjetivam-se no discurso do agronegócio. Orlandi (2017, p. 33) diz que "saber já é identificar-se" pelo modo de subjetivação. É o que se pode perceber quando Gilson Wolf diz:

\footnotetext{
A gente é o pequeno agronegócio (...) porque aqui o feirante planta verdura, planta legumes, tem produção de leite, criação porcos, galinha, a pessoa vive disso e é o pequeno da parte do agronegócio, não é dos grandes fazendeiros, dos grandes proprietários, mas é do agronegócio.
}

Percebe-se nas falas dos feirantes que os sentidos resultam das relações e que seus efeitos não se produzem na formulação agronegócio, mas sim na modulação do tamanho da propriedade e da quantidade da produção. Pequeno ou grande produtor, todos são agronegócio. Toda pessoa que devota sua vida a cultivar a terra é agronegócio - pequeno ou grande. É o discurso transformando, reformulando as relações sociais. $\mathrm{O}$ mesmo pode ser percebido na fala de Beno Asseburg: 
Pequeno ou grande, tudo é agronegócio. Como é que diz a propaganda da Globo? Ela diz, agro é tudo. E é isso mesmo. É isso que somos. No fim tudo vem do produtor. Industrializado ou não, tudo vem do produtor. Eu sou agricultor familiar,' sou pequeno agricultor, sou agronegócio, claro.

Henry (1993, p.25) explica que as dissimetrias e as dissimilaridades entre os agentes de produção do sistema de produção não se produzem de modo explícito: "coloque-se aqui, este é seu lugar no sistema de produção". A partir desta observação é possível pensarmos que não foi dito aos feirantes "coloquem-se como agronegócio, este é o seu lugar" ou "coloquem-se fora do agronegócio, este é o seu lugar”. Em uma região na qual o agronegócio está muito presente no cotidiano, o feirante se diz agronegócio, perante o conjunto de possibilidades de sentidos que se abrem e são possíveis, uma vez que, segundo Henry (1993, p.23) “a ideologia é um processo que produz e mantem as diferenças necessárias ao funcionamento das relações sociais de produção em uma sociedade dividida em classes". É pela ideologia e pela história que os feirantes reconhecem-se como pequeno agronegócio. Eles compartilham uma memória comum, levando em conta a historicidade, o que remete à explicação de Orlandi:

defino a narratividade como a maneira pela qual uma memória se diz em processos identitários, apoiados em modos de individualização do sujeito afirmando/vinculando seu pertencimento a espaços de interpretação determinados, consoantes a específicas práticas discursivas (ORLANDI, 2017, p. 30)

Podemos, então, compreender que as imagens que os feirantes atribuem a si e ao agronegócio são determinadas pelo lugar em que estão. Apesar de entenderem o agronegócio como sendo a grande produção, reconhecem-se na atividade, encontram semelhanças que os fazem comuns. O que nos permite perceber o conceito de formações imaginárias, explicado por Pêcheux (1993, p. 82) quando ele afirma que essas "designam o lugar que A e B se atribuem cada um a si e ao outro, a imagem que eles fazem do seu próprio lugar e do lugar do outro". Se o agronegócio é a interrelação entre o 'antes', o 'dentro' e o 'pós' porteira, não importa a quantidade, o tamanho dessas relações, mas sim que elas se efetivem. No discurso dos feirantes, os grandes produtores são agronegócio e os pequenos também, já que todos desenvolvem uma atividade de relevância econômica no âmbito rural: um negócio agro.

\section{Negócio agro familiar}

Oliveira (1983), em um estudo da pequena produção em Sinop, destaca que "a presença do capital no campo, especialmente na pequena produção de base familiar, se evidencia inicialmente pela mercantilização, isto é, pelo caráter da pequena produção produzindo para o 
mercado". Os feirantes são facilmente associados à agricultura familiar dentro do jogo de imagens sobre como eles se vêem e como são vistos. Um funcionamento semelhante ao que produz os sentidos de agronegócio como apenas sendo a grande produção. Mas é possível pensarmos também sobre essa formulação. Sobre os sentidos possíveis em agricultura familiar.

\begin{abstract}
A utilização de termos específicos nos estudos teóricos e empíricos ligados ao rural carece, muitas vezes, de uma reflexão mais criteriosa acerca de seus significados. Termos idênticos utilizados por pessoas diferentes podem acabar recebendo um tratamento/definição distinto(a); por outro lado, termos distintos também podem receber tratamento como análogos quando usados por pesquisadores/intelectuais diferentes. (BREITENBACH E SILVA, 2013, p.64).
\end{abstract}

Observamos aqui um espaço de interpelação pela ideologia, compreendendo a afirmação de Pêcheux (2014, p.193) de que as formações ideológicas são inerentes às relações de produção capitalistas. É a ideologia que fornece as evidências para que uma formulação "queira dizer o que realmente diz" (2014, p. 146). "O caráter material do sentido - mascarado por sua evidência transparente para o sujeito - consiste na sua dependência constitutiva daquilo que chamamos o todo complexo das formações ideológicas".

Através do funcionamento de um discurso jurídico governamental, a agricultura familiar é dita aquela que compreende atividades no meio rural, com área de até quatro módulos fiscais, mão de obra da própria família e renda vinculada ao próprio estabelecimento e gerenciamento do estabelecimento ou empreendimento por parentes. Também entram nessa classificação silvicultores, aquicultores, extrativistas, pescadores, indígenas, quilombolas e assentados da reforma agrária. Nota-se que a Lei 11.326/2006 faz referência ao tamanho da propriedade: quatro módulos fiscais. Cabe ressaltar que essa é uma unidade de medida de área expressada em hectares e que se difere de um município para o outro. Segundo o Instituto Nacional de Colonização e Reforma Agrária (Incra), um módulo fiscal, em Sinop-MT, equivale a 90 hectares. Em Benevides-PA, por exemplo, um módulo fiscal equivale a sete hectares. Os números sugerem a reflexão sobre o que é uma grande ou pequena propriedade rural, visto que a perspectiva pode mudar de um município para outro, de um Estado para outro.

E se o que se coloca em reflexão aqui é o tamanho da propriedade para que se enquadre como agricultura familiar ou não, por que não lançarmos o olha sobre o enunciado familiar. $\mathrm{O}$ Dicionário Aurélio define família como conjunto de todos os parentes de uma pessoa, e, principalmente, dos que moram com ela. Familiar é, portanto, aquilo que se refere à família. 
Percorrendo as bancas das feiras realizadas pela Afes é possível perceber a presença de diferentes gerações, reforçando o caráter familiar e evidenciando os sentidos de agricultura familiar para o feirante Gilson:

A agricultura familiar é em família. E realmente a maioria do pessoal produz em família, em casa. A família toda trabalha em casa e na feira vem um representante da família. Geralmente é a família e mais algumas pessoas, como funcionários. As bancas vão passando de pai para filho e de filho para neto.

Percebe-se que os sentidos de familiar não estão no tamanho da propriedade ou na quantidade da produção, mas sim nas relações entre as pessoas que trabalham na propriedade, tornando possível pensar que a atividade em uma latifúndio com larga produção também pode ser uma atividade agropecuária em família, uma agricultura familiar. Sentidos possíveis que estão presentes na afirmação de Oliveira e Stédile (2005) que afirmam que há uma luta entre dois modos de organizar a produção agrícola.

É comum vermos artigos e reportagens cantando em prosa e verso as belezas do agronegócio. Alguns intelectuais, inclusive com origem na esquerda, defendem que a saída para a pequena agricultura seria também entrar no agronegócio. E alguns sindicalistas copiaram mal essa idéia e chegam a falar em "agronegocinho" (OLIVEIRA E STÉDILE, 2005, p 33).

Da mesma forma que há um pré-construído de que o agronegócio refere-se aos latifúndios, a Lei define que a agricultura familiar não é aquela que é desenvolvida pelas família, mas sim aquela que acontece em pequenas áreas. Nas grandes propriedades, a presença de membros de uma mesma família atuando justificaria a utilização do termo agricultura familiar. Portanto, a família pode trabalhar não somente em pequenas propriedades, mas também nos latifúndios.

\section{Efeito de fecho}

Podemos observar que as feiras são importantes nos contextos econômico e social do município de Sinop, configurando-se como espaços de trocas materiais e interações culturais. Percebemos que há divergências entre o que agronegócio e agricultura representam no senso comum e na forma como são apresentados na discursividade dos feirantes sinopenses. Compreendemos que o sentido de agronegócio no relato dos dois feirantes que integram esta pesquisa apresenta-se estabilizado, como constitutivo dessa posição, apresentando apenas as modulações grande agronegócio e pequeno agronegócio. 
No que se refere à agricultura familiar, os sentidos formulam-se nas relações entre as pessoas que atuam na propriedade rural e não no tamanho da propriedade ou na produtividade.

\section{Referências}

ARAUJO, WEDEKIN e PINAZZA, Ney Bittencourt, Ivan e Luiz Antônio. Complexo agroindustrial: o "agribusiness" brasileiro. Agroceres, 1990.

BREITENBACH, Raquel; SILVA, Alexandre. O debate agricultura familiar versus agronegócio: as jaulas ideológicas prendendo os conceitos. In: Revista Extensão Rural, Santa Maria: UFSM, 2013, p.61-85.

DICIONÁRIO AURÉLIO. Disponível em: https://dicionariodoaurelio.com/familia Acesso em: 28. nov.2018.

MATO GROSSO. Disponível em: www.mt.gov.br Acesso em: 17.jun.2018.

HENRY, Paul. Os fundamentos teóricos da "Análise Automática do Discurso" de Michel Pêcheux (1969). In: GADET, Françoise; HAK, Tony (orgs.) Por uma análise automática do discurso: uma introdução à obra de Michel Pêcheux. Campinas: Editora Unicamp, 2014, p.11-38

INCRA. Tabela clom Módulo Fiscal dos Municípios. Disponível em: http://incra.gov.br/tabela-modulo-fiscal. Acesso em: 24.jun.2018.

MENEZES, Vicente de Paulo Lima. As feiras-livres em Fortaleza - retrato da polissemia urbana. Agosto - 2005. Disponível em http://www.uece.br/mag/dmdocuments/vicente_menezes_dissertacao.pdf Acesso em 26.nov.2018.

MINISTERIO DE DESENVOLVIMENTO AGRÁRIO. Agricultura familiar do Brasil é 8 maior produtora de alimentos do mundo. Disponível em:

http://www.mda.gov.br/sitemda/noticias/agricultura-familiar-do-brasil-\%C3\% A9-

8\%C2\%AA-maior-produtora-de-alimentos-do-mundo. Acesso em: 21.jun.2018.

OLIVEIRA, João Mariano de. A esperança vem na frente: contribuição ao estudo da pequena produção em Mato Grosso, o caso de Sinop. São Paulo: 1983.

OLIVEIRA, A. U.; STEDILE, J. P. A natureza do Agronegócio no Brasil. In: Publicação da Via Campesina Brasil. Fórum Nacional de Reforma Agrária, 2005.

ORLANDI, Eni. Análise do discurso: princípios e procedimentos. Campinas: Pontes, 2015.

ORLANDI, Eni. Eu, Tu, Ele - Discurso e real da história. Campinas: Pontes, 2017. 
PÊCHEUX, Michel. Semântica e discurso: uma crítica à afirmação do óbvio. Campinas: 2014.

PEREIRA, V. Brito, T. A feira-livre como importante mercado para a agricultura familiar em Conceição do Mato Dentro (MG). Disponível em http://www.rchunitau.com.br, Acesso em 20.nov.2018.

SOUZA, Edison Antônio de. O poder na fronteira: hegemonia, conflitos e cultura no norte de Mato Grosso. Cuiabá: EdUFMT, 2013.

SOUZA; THOMAZ JUNIOR. A Dimensão Espacial do Discurso do Agronegócio e a Expansão do Capital no Campo. In: Revista OKARA: Geografia em debate, v.6, n.1, p. 122-140, 2012. Disponível em: http://www.okara.ufpb.br. Acesso em: 19.nov.2018.

Recebido em 30 de dezembro de 2018. Aceito para publicação em 21 de maio de 2019. 